\title{
The "Micromorphological" Dissemination of Art Works in the Context of New Media
}

\author{
Fang Li \\ School of Fine Arts \\ Chengdu Normal University \\ Chengdu, China 611130
}

\begin{abstract}
In today's society, the quickening of life and the heavy workload make it impossible for people to take some time to concentrate on a certain matter. The popularity of the Internet, mobile phones and palmtop computers enables people to access information quickly and efficiently through multiple ways. Therefore, the "micromorphological" art works spread by Weibo, WeChat came into being. It adapts to the pace of the development of fast food culture in the whole society and caters to the psychological needs of the masses to show themselves and express their individuality.
\end{abstract}

Keywords—new media; art works; micromorphology; spread

\section{INTRODUCTION}

There are four ways of disseminating art works: "first, to sell or give; second, to be attached to buildings, public places or household objects and then spread around the world; third, to be published by the media; and fourth, to exhibit." [1] The first, second and fourth ways have existed since ancient times. With the development of art communication mode, media publishing has become an effective way to disseminate contemporary art works.

\section{THE "MiCROMORPHOLOGY" OF THE CARRIER OF FINE ARTS COMMUNICATION}

In today's society, the quickening of life and the heavy workload make it impossible for people to take some time to concentrate on a certain matter. The popularity of the Internet, mobile phones and palmtop computers enables people to access information quickly and efficiently through multiple ways. The emerging network media complement the traditional media from real-time interaction, non-linearity, hyperlink and other aspects. Therefore, the "micromorphological" art works spread by Weibo, WeChat came into being. It adapts to the pace of the development of fast food culture in the whole society and caters to the psychological needs of the masses to show themselves and express their individuality. At the same time, the figurative appearance of art works determines that the examination of art works requires the stay and taste of vision, and the "micromorphological" communication is more advantageous to the examination of art works than the dynamic film communication of film and television.
In order to adapt to the change of popular reading habits, many magazines and newspapers have also changed their communication strategies, and many traditional paper media have grafted mobile clients to enhance the interactivity of art appreciation. For example, the Art News launched the "Micro Art" interactive special page on the Internet, combing and commenting on the most popular art Weibo information in time, breaking the trivial and static appearance of traditional news. [2] The new media, Weibo and WeChat, have greatly changed the original style, type, form and dissemination of art works. The "micromorphology" has changed the traditional art works of existence, communication and acceptance, so that it has acquired a unique communication charm.

\section{THE TIME ADVANCE OF THE MICROMORPHOLOGICAL DISSEMINATION OF ART WORKS}

1. The "micromorphological" communication mode of can make fine arts works spread in a wide range and over a long distance in different contexts, extending the platform of art works dissemination, transcending the limitation of time and space of art works, with a quick spread, a wide range, and high efficiency. Through copying, pasting, sharing, forwarding and other "one-to-many" fission modes of communication, new activities, exhibitions and new works of artists, all can be spread through Weibo and WeChat in a timely manner, expanding the range and level of the audience. The "micromorphological" media of this art works accord with the popular taste, popularization and entertainment, and meet the needs of the civilian spirit and the taste of knowledge. At the same time, the "micromorphological" dissemination of art works can also promote the popularization of relevant knowledge of art market through the introduction of investment, collection and transaction of art works, thus promoting the development of art trading market and cultural industry.

2. The "micromorphological" dissemination of art works makes it easier for the public to appreciate art works and increase the affinity. Any person has the right to speak to the "micromorphological" art works published on the network, which do not need any expert, the audit of the organization published anytime and anywhere, breaking the monopoly position of the traditional art critic. Some amateur art lovers' comments can be widely circulated through the Internet, and these amateur art lovers become well-known art critics. These 
popular art critics have not received professional art theory education, and their comments are mostly expressed in the sensibility of liberalization, showing the truest emotional vent. Thus, the deconstruction of the methodology of the traditional art criticism system is produced, and enhancing the affinity of the art works. The "micromorphological" media has brought the democratic participation of the public discourse in the art criticism, subverted the right of the authoritative art critics to speak, and deconstructed the language mode of the traditional media criticism. It reconstructs the language system of art review under the medium of Micromorphology.

3. The "micromorphological" dissemination mode of art works has diversified forms of presentation, which can be presented in groups or in one piece, and can also be illustrated with pictures and texts. The "micromorphological" communication mode of art works has diversified forms of presentation, which can be presented in groups or in one piece, and can also be illustrated with pictures and texts. However, no matter which presentation mode, it has the function of technological reproduction. But the art works after the reproduction and dissemination of Weibo, WeChat and those published on Weibo and WeChat for the first time have no difference in aesthetic sense and also show some innovation in the reproduction technology. Jacques Derrida once said, "if something beautiful is lost by copying nothing, if one can find beauty in its symbols, it is because," The 'first' creation of beauty already contains the nature of reproduction. "[3] Weibo, WeChat, which is a "micromorphological" art communication mode, can reproduce and spread most of the original works of art without restriction, thus making the original works of fine arts have the value orientation of public communication. The art replica also obtained a kind of art media text identity.

4. The "micromorphological" spread of art works leads people to change their understanding of art works. This "micromorphological" communication uses new language symbols to re-encode, display art works with the most infectious words or pictures, subvert the grand narrative means of mainstream media, and mark the rise of a popular culture. Some art nobodies or non-professional art lovers can post their works or comments on Weibo or WeChat. In this "micromorphology", everyone has the right to give a speech freely, and this "micromorphology" spreads quickly, interactively with no entry threshold. In this platform, everyone's opportunities for display are equal, not restricted by fame and artistic style. This mode of dissemination of information makes traditional art works of majestic and academic nature peel off serious coats. Going to the public has changed people's understanding of traditional art works.

\section{The Cultural DeCONSTRUCTION OF THE "MICROMORPHOLOGICAL" SPREAD OF ART WORKS}

1. The "micromorphological" spread of art works easily makes the subject of art works as a virtual existence. Before the art works are published on Weibo, WeChat, it is necessary to collect the images of the works of fine arts, to process the image size, color, light and dark through the camera and graphics processing software, and then through Weibo, WeChat has released art works and made them into video art displayed on electronic screen. The audience receives the virtual images of the art works, rather than the original works of art. This "micro form" is a solution to the origin of the works of art.

2. The mass reproduction and broadcast of "micromorphological" art works and the popular vulgarization of "micromorphological" comments have dispelled the sublime feeling brought by the exhibition works of the traditional art gallery and the elegance of the fine arts works themselves. "Although we can hope that art will continue to flourish and become more perfect, the form of art is no longer the highest need of the soul. Although we find the Greek gods beautiful, and the Father, Christ and Mary appear majestic in art, they are all in vain, and we no longer bow to their knees. "[4] The public's aesthetic taste for art works has changed from reverence to contemplation into memoryless "likes" and random comments, the strong interactivity of "microcommunication". The creators of art works have also become consumers of art works, breaking the limitation of identity, resulting in the "deconcentration" of fine arts works, and dispelling the "sense of nobility" of art works. This results in the fragmentation of the signifier and the signified in the works of fine arts. The "copy" mode of communication, which brings aesthetic subversion to the traditional art creation principles, may make the art works become a semantic schema of sacrificing spiritual text.

3. The "micromorphological" dissemination of art works deconstructs the traditional art criticism system, which impinges on the position of the art critics who have the authority to speak in the traditional sense, and weakens the public's dependence on these critics. In this kind of "micromorphological" dissemination, anyone has a right to speak, and whose comments on art works published directly without the approval of any organization or expert. However, these popular commentators basically do not have perfect professional knowledge and academic accomplishment. Most of the commentaries published are of low quality and mixed up, leading to the amateurization of academic essence, so that the public need more time and energy to "identify false things, retain the real things", "eliminate the rough and refined", easy to cause a new waste.

4. Some art creators deliberately pursue the taste of the media, seeking for new and difference, resulting in the loss of aesthetic value of art works. In this rapid expansion of information age, art creation is more easily dominated by market consumption, some minor art creators to meet the needs of the market and continue to copy their own works; some other art creators, who are not well known, taking a different approach, making works that are different without aesthetic value; also some art creators who are not highly cultivated, pay people to write fake articles to raise their worth. Most of these art creators lack the ability to resist interference of information and pursue the spirit of art persistence. In addition, "micro-information" spreads quickly and has a wide range, which makes these art creators unable to withstand the temptation of various kinds of information, appearing a bit impetuous and eager for immediate benefit. So it is difficult to hammer out a high aesthetic work of fine arts. 


\section{THE CONSTRUCTION OF THE SPREADING ECOLOGICAL ENVIRONMENT OF THE FINE ARTS' "MICRO-MORPHOLOGY"}

1. In the context of new media, through Weibo, WeChat and other "micro-platforms", art works are better spread from the private to the public domain, and strive to construct the public cultural field space of art communication. On the one hand, in the "micromorphological" medium of art works, Weibo, WeChat and other media provide corresponding material carrier for art works, and turn art works into public cultural products; on the other hand, through the "microplatform" such as Weibo and WeChat, the art works have the characteristics of public communication. Therefore, art works through the "micro-platform" media transmission, can become cultural media products. The construction of the public field space of art communication is the embodiment of the communication value of art works in the mass media, and the art communication value in the media context. Get rid of that kind of religious worship, show more trend of democratization of art aesthetics.

2. Strengthen the construction of media management system for the dissemination of fine arts "micromorphological" works. In the field of fine arts media, the principle of combining state supervision with self-management should be followed. From the aspects of the form, means, method and process of national cultural administration, a series of standardized and effective procedures are established, some blind, oversized and empty works of fine arts are filtered out to spread information, and the media behavior of the dissemination of art works is reasonably regulated. The audience of art works should also be motivated to take the social responsibility actively, give full play to the right of the audience to speak, and promote the transformation from the unbalanced state to the balanced state.

3. Through the social mainstream media to carry on the positive public opinion propaganda, it strengthens the audiences' ability of dissemination information and identification, and the rational thinking ability, Let the audience know how to search for valuable works of fine arts in the mass of information to reward and comment, and improve the audience's ability to accept the works of fine arts. In addition, the management agencies of the news media should strengthen the supervision and control, through the integration of information, we should put an end to taking out of context, reproduce the integrity of art works, give play to the authoritative role of the mainstream media. Therefore, we can make the information transmitted more objective, truthful and effective, reducing some fomenting works of art hype information, to avoid rumors spread and restore the truth.

\section{CONCLUSION}

The "micromorphological" dissemination of art works not only dispels the beauty of art itself, but also extends the extension of art. The "micromorphological" dissemination of art works should truly reproduce the aesthetic characteristics of art works and reconstruct the value of art works in the process of resolution. Through the pursuit and reflection of the new media science and technology and the market economy culture, the "micro - form" mode of communication of the art works really becomes the soul carrier which expresses the ultimate concern of the art, not the commercial marketing technique in the technological era. When more and more people accept the "micro-morphological" communication mode of art works, it is more and more conducive to creating a strong cultural environment for the dissemination of "Noumenon" of art works, which is the aesthetic significance of the "micromorphological" dissemination of art works.

\section{REFERENCES}

[1] Deng Fuxing. About Art Exhibitions, Selection And Others [J]. Art Watch,2000. (2): 48-49. 邓福星.关于美术展览、评选及其他 [J].美术 观察,2000, (2) :48-49.

[2] Ye Yuyue. When Art Encounters "Micro"-Analysis Art Newspaper "Micro Art" Interactive Special Edition [J]. The News Practice, 2013(8): 70-71. 叶玉跃.当艺术遭遇 “微”--析美术报《微艺术》互动专版 [J]. 新闻实践, 2013, (8) : 70-71.

[3] Jacques Derrida. On Philology [M]. Wang Tangjia Translated. Shanghai: Shanghai Translation Press 1999: 302. 雅克・德里达.论文字学[M].汪 堂家泽. 上海: 上海译文出版社, 1999:302.

[4] Hegel. Aesthetics [M]. Zhu Guangqian translated. Beijing: Business Press, 2008: 132. 黑格尔.美学 [M]. 朱光潜译. 北京: 商务印书 馆, 2008:132 